\title{
The extensions of man revisited. From Primary to Tertiary Embodiment
}

\author{
Göran Sonesson, \\ Department of semiotics \\ Lund University
}

Contemporary references to the notion of embodiment seems to have very little to do with what I would like to call the classical discussion of embodiment, which occupied the philosophers at the turn of the $19^{\text {th }}$ century. First of all, the contemporary views only concern what I will here term primary embodiment: the fact of the subject realising that he (unlike the angels, as Scheler puts it) has a body and, beyond that, that this body is so to speak the condition of access to the experience of the world. The mystery to observers of our day is rather than we also have a mind - which to many of them is so mysterious that they prefer to deny it or, what amounts to the same, describe references to the mind as being just a convenient mode of speaking. The classical discussion of embodiment also involved what I will here name secondary embodiment, which is ignored in the contemporary discussion, but which formally constitutes the model for it: for it concerns the curious fact that some of the objects of the outside world which I perceive are also minds for whom I am in the same way an object. Finally, classical embodiment theorists were very much preoccupied with what will here be dubbed tertiary embodiment: that some products of the mind may come to exist independently of individual minds, but only by gaining a material dimension, by becoming, in the words of Charles Sanders Peirce, "brute facts", or, in Hegelian and Marxian terminology, by being "reified".

It is no accident, as we will see, that these embodiment types are distributed as the personal pronouns: they concern Ego, Alter, and Alius. Since I am involved with semiotics, tertiary embodiment will be my particular concern here. Indeed, primary embodiment will be considered in relation to the tertiary one, but secondary embodiment will be ignored for the purpose of this paper.

\section{The body, old and new}

The best way to explain the difference between the classical conception of embodiment and the uses to which the term has been put more recently (which, to, to my mind, are either fuzzy or redundant) is no doubt to take our point of departure in phenomenological philosophy. In the philosophical tradition, embodiment emerges as a problem out of the assumptions of the philosophy of consciousness, which aims to reconstruct the world as given to a (arbitrary or 
generic) subject. In this sense, embodiment gives rise to two separate strands in the particular version of the philosophy of consciousness, inaugurated by Edmund Husserl, know as phenomenology: in relation to the physical body of the subject itself and/or his or her counterpart in perceptual space, the generic other (that is, primary and secondary embodiment, respectively); and in relation to signs and other overarching structures which, like the physical body, appear in the mind, without being of the mind, and often seem to require some kind of physical substratum in order to exist (our tertiary embodiment).

The justification for a philosophy of consciousness is of course that, in the ordinary common sense world, which Husserl later was to baptise the Lifeworld, everything there is is accessible to us through consciousness; but the paradox is that, at the same time, the body, our own, as well as that of the other, does not seem to be a mere figment of consciousness. To reverse the common saying stemming from the biological and psychological tradition of the last century, the body is not a mere epiphenomenon of consciousness. Indeed, this transcendence of our physical being to the Lifeworld is itself part of the Lifeworld: as Max Scheler nicely put it, we know that we are no angels (that is, no free-floating sprits without bodies).

The second strand is quite different: genuine semiotic structures such as mathematics, logic, and even language appear to transcend consciousness much in the mode of a Hegelian absolute spirit: they are, in Husserlean terms, "idealised" in order to be detached from their dependence on individual subjects - which is why they may harbour what Deacon (2003) has recently called "semiotic constraints", whose origin is independent of both nature and nurture. And yet, as Husserl (1962a, 365-386) recognised in his study of the origin of geometry, for the idealisation to be complete, its products have to be embodied in some kind of notational system, because only in that way can they gain a stable, public existence in a domain completely separate from their instantiations in the practical situations of the Lifeworld. More recently, thinkers from quite different traditions, such as Ivins, Innis, Goody, and Donald, have regained this insight in some form or other (cf. Sonesson 1989, 30ff).

The task of phenomenology, as Husserl saw it, was of course to explain the possibility of human beings having knowledge of the world: as a philosophical endeavour, phenomenology is about the way the world of our experience is "constituted" for us. But every finding in phenomenological philosophy, Husserl claims, has a parallel in phenomenological psychology, which thus could be considered a tradition within psychological science (cf. Husserl 1962b; Gurwitsch 1974). It is often forgotten that Husserl himself not only inspired but also was inspired by the Gestalt psychologists. Close followers of Husserl such as, most notably, Aron Gurwitsch $(1957 ; 1966)$, were as much involved with phenomenological 
psychology as with philosophy and discussed the findings not only of the psychology of perception but of contemporary contributors to neurobiology such as Gelb and Goldstein. Also the early Merleau-Ponty (who may not quite deserve the hero status given to him by Varela, Thompson \& Rosch 1991) was, in this respect, an exponent of phenomenological psychology, although he probably never used the term.

Those who today are concerned with embodiment appear to come from the diametrically opposite camp. Gerald Edelman (1992), for instance, talks about embodiment in a very loose way. However, he clearly does not discover the body from the horizon of consciousness, but quite the opposite. To him, therefore, the body is not a meaning, not an experience given to the mind. He obviously means to imply that the mind cannot be divorced from the body. In a sense, this is hardly controversial: unlike those hypothetical angels, humans can only boast a mind as long as they have a body. But, if this is true in the order of existence, it is not necessarily so from the point of view of investigation. After all, Franz Brentano did not use a scalpel, much less an EEG or an MEG, to discover the property of intentionality (in the sense of directedness), which Edelman recognises as an irreducible characteristic of consciousness; nor did William James find any of those "Jamesian properties" of consciousness repeatedly mentioned by Edelman in such a way.

Indeed, far from being "a deliberately non-scientific set of reflections on consciousness and existence" (Edelman 1992, 159), phenomenology started out from the fact of intentionality and attempted to probe ever deeper into its ramifications, in order to rediscover and amplify (in particular in the work of Gurwitsch) those very Jamesian properties of consciousness mentioned by Edelman. Husserl and Gurwitsch may have been wrong to think of phenomenology as a discipline apart from biology and psychology (and for my part, at least, phenomenological psychology is quite enough), but the relative disconnection of phenomenological reflections, like those of Brentano and James, from biological knowledge has no doubt borne rich intellectual fruit (more so, I believe, that the elucubrations characteristic of "phenomenology of the post-Husserlean varieties" epitomised by Johnson 1987,xxxvi). If "a biologically based theory of mind" can in some respects "invigorate" phenomenology, the opposite is certainly just as true.

But first, of course, we have to be looking at the same body, from the same perspective. Interestingly, like Merlin Donald (1991) in a recent book, Edelman (1992; \& Tonini 2000) claims that consciousness as such cannot be a spurious occurrence, because that would not have made evolutionary sense. That is, consciousness is not an epiphenomenon. But we have seen that, to classical embodiment theory, the problem is to show that the body is not an epiphenomenon. 
The paradox arises because, in the two cases, the point of view is entirely different. Phenomenology, like the science of semiotics, takes as its point of departure the way things make sense to us, that is, how they mean. In this, very broad sense, phenomenology accomplishes a semiotical reduction: ${ }^{1}$ things are considered only from the point of view of their having meaning to us (where "we" might be people of a particular culture or subgroup, or humankind in general). From a phenomenological point of view, there is, in a sense, no way of overcoming the divide between the body and the mind formulated by Descartes, for Descartes did not invent it: it is intrinsic to that phenomenon which, in Descartes' own words, is the most widely distributed one in the world: common sense. ${ }^{2}$

Common sense is not notorious for being right: but if we ask ourselves how the body (and the rest of the world) makes sense to us, then common sense is our very subject matter. Even so, common sense gives rise to an apparent contradiction: my body is necessarily experienced through my consciousness, but in my consciousness it is experienced as being outside of it. ${ }^{3}$ All post-Cartesian mediations, from those of Husserl to those of Merleau-Ponty, have been concerned to account for this paradox. To do so, it is necessary to accomplish a painstaking analysis (of which there can by no better example than the posthumous papers of Husserl himself, together with the - also largely posthumous - works of Peirce ${ }^{4}$ ) of all those structures of the mind which are normally at the margin of consciousness. Since this is a question of discovering the way in which that which has a meaning means, there is no other way of achieving it, even if it is an extremely fallible enterprise.

So we are concerned, then, in the first place, with the figure of the body as it appears on the horizon of consciousness. Once we have described this figure - better than James, Husserl, and so on -, we may try to explain it, delving ever deeper into the margins of consciousness. We can of course try to search for explanations outside of consciousness, but we must be aware that this is a complete change of direction.

Contemporary theories of embodiment do not appear to pose the question of meaning. Varela, Thompson \& Rosch (1991) start out from the phenomenology of Merleau-Ponty, but, after the first few pages, it is not really clear how the issues they discuss relate to the phenomenological problem of the body. Lakoff \& Johnson $(1999,102)$ distinguish three different levels of embodiment which they refer to as "the neural level, phenomenological conscious experience and the cognitive unconscious", but, judging from all what is said later on, the intentional depth of their notion of phenomenology appears to be extremely shallow. In the end, we have to return to Edelman to be assured that consciousness is not an epiphenomenon.

Our problem, however, is to show that the body is not an epiphenomenon - and that 
primary embodiment, understood in this way, may serve as a stepping-stone for the interpretation of secondary and tertiary embodiment. Even if what has been written about embodiment in contemporary literature seems to me to be of little help in this endeavour, other present-day thinkers coming out of the tradition of biology and cognitive science, such as Merlin Donald and Terry Deacon, may offer important insights, when their contributions are critically assimilated - very critically, as we will see. They form part of a tendency in cognitive science which I have elsewhere (Sonesson 2003a) termed the "semiotic turn": the discovery of the importance of signs (or the semiotic function) and meanings to human evolutionary history.

\section{From the portable memory to the independent record}

Let us therefore start out from the contemporary socio-cultural Lifeworld inhabited by all kinds of signs and meanings, and ask ourselves how, from this point, we may get back to earlier layers of meaning accounting for the possibility of this world which, in many respects, is so different from that of other animals - the world of straight-forward semiotic phenomena such as language, gesture, and pictures. ${ }^{5}$ Is has been suggested by Merlin Donald (1991; 2001) that, both phylogenetically and ontogenetically, there are several discontinuities in the development which leads from non-human animals to human beings, all involving the acquirement of a distinct kind of memory, considered as a strategy for representing facts. Without necessarily taking every details of Donald's scheme at face value, I am going to make use of it here, because it accounts for a lot of facts, while also permitting a productive integration with semiotic theory. Indeed, as we shall see, both the Prague school and the Tartu school of semiotics have often conceived of meaning in terms of memory.

According to Donald's conception, many mammals, who otherwise live in the immediate present, are already capable of episodic memory, which amounts to the representation of events in terms of their moment and place of occurrence. The first transition, which antedates language and remains intact at its loss (and which Donald identifies with homo erectus and wants to reserve for human beings alone) brings about mimetic memory, which corresponds to such abilities as the tool use, miming, imitation, co-ordinated hunting, a complex social structure and simple rituals. This stage thus in parts seems to correspond to what I have elsewhere (Sonesson 1992a,b and below) called the attainment of the semiotic function (though Donald only notes this obliquely, in talking about the use of intentional systems of communication and the distinction of the referent). Yet, it should be noted already at this point that while all abilities subsumed in this stage seem to depend on iconic relations (perceptions of similarity), only some of them are signs, because they do not involve any asymmetric relation between an expression and the content for which it stands. ${ }^{6}$ 
Only the second transition brings about language (which, Donald muses, may at first have been gestual) with its semantic memory, that is, a repertory of units which can be combined. This kind of memory permits the creation of narratives, that, is mythologies, and thus a completely new way of representing reality. Interestingly, however, Donald does not think development stops there, although there are no more biological differences between human beings and other animals to take account of. However, the third transition obviously would not have been possible without the attainment of the three earlier stages. What Donald calls theoretical culture supposes the existence of external memory, that is, devices permitting the conservation and communication of knowledge independently of human beings. The first apparition of theoretical culture coincides with the invention of drawing. For the first time, knowledge may be stored eternally to the organism. The bias having been shifted to visual perception, language is next transferred to writing. It is this possibility of conserving information externally to the organism that later gives rise to science (cf. Fig. 1).

[Fig. 1.]

There are two remarkable features in Donald's analysis. The stage preceding the attainment of the language capacity requires memory to be located in the own body. But, clearly, it can only function as memory to the extent that it is somehow separable from the body as such. While being in the body, it is not of the body. In fact, this can only be so, to the extent that some memory traces are instantiated in other bodies as the same time as in the own body. This supposes a distinction between token and type (that is, relevance separating those features which count and which are repeated from all the rest) preceding that of the semiotic function.

The stage following upon language supposes the sign to acquire a body of its own, in the strongest sense of the term: the ability to persist independently of human beings. Language only seems to require the presence of at least two human beings to exist: they somehow maintain it between them. But pictures must have a body of their own. They must be divorced from the bodies (and minds) of those making use of them. ${ }^{7}$ As Husserl noted well before Donald, material embodiment is necessary also for science, starting with mathematics and logic. Independently of both, Ivins (1953) pointed out that it is the reproducibility of pictures (as in Floras, for instance) which transforms them into scientific instruments. In this sense, in their capacity of being permanent records, pictures are not, as art historians are wont to say, unavoidably unique, but, on the contrary, are destined for reproduction. Indeed, they permit repeated acts of perception, as do no earlier memory records. The development of the capacity for reproducing the record itself has a long history recently giving rise to xylography, photography, and the computer picture. 
Students of prehistoric pictures (such as White 2000) often suggest that creators of such works must have been capable of language. In fact, not much can be concluded on the basis of the depictions having come down to us: even though pictures, by their nature, must have been made on material which conserve the markings on the surface, they might at first have been created on surfaces (such as sand) which only preserve them for a short time. And it is not easy to establish any clear-cut relation between the language capacity and the sophistication of the depictions (whatever that is). There are, however, more fundamental reasons for supposing pictures to be later in development than language: they suppose a record which is independent of the human body; and they require us to see a similarity within an over-arching dissimilarity.

Within semiotics proper, the Tartu school has observed that the accumulation of information as well as of merchandise precede their interchange and is a more elementary and more fundamental characteristic of a culture. According to Lotman et al. (1975), material objects and information are similar to each other, and differ from other phenomena, in two ways: they can be accumulated, whereas for example, sleep and breathing cannot be accumulated, and they are not absorbed completely into the organism, unlike food, but they remain separate objects after the reception. Here Lotman seems to treat the sign as pure information, perhaps because he thinks mainly about verbal texts, where the material base is extremely changeable. More obviously, a picture is as much a material object as information, as much an artefact as an object of perception. This is why we can accumulate pictures in a double sense: as material things, in the safe-deposit box of a bank, or like experiences in the mind. In both senses they maintain a certain distance with respect to the body.

Some of the characteristics that Lotman attributes to information brings to memory those which are mentioned by Masuda (1980), one of the first propagandists of information society: in his view, information is not consumable, no matter how much it is used, but it can be transferred to a new place without disappearing from the point of origin; it is not accumulated if it is not used as it is the case of material goods but, on the contrary, by being used increasingly and being integrated with other information. Against Masuda as much as against Lotman it is possible to object that even the most elusive kind of information must be incarnated in some type of material substance, quite apart from the fact that all access to the information in question depends on some material apparatuses called computers, hard discs and compact disc player. In the world of ideas the content of a book exists indefinitely; but in reality, it evaporates with the last paper copy which moulders away or the last person that dies or forgets the content. It could be argued, however, that while the first case is feasible in the case of books (and of language systems which disappear when the last speaker dies - or, 
rather, when the last two speaker do), only the second case applies to pictures. Pictures must really be conserved in a material form independent of the human body. ${ }^{8}$ Today, that material form may very well be a computer record. But also computerised information is dependant on the wear of the units of storage such as compact discs and hard discs.

In this sense all information goods are temporarily limited - even though some limitations can be of relatively long duration. Roland Posner (1989) distinguishes two types of artefacts: the transitory ones (which are characteristically exemplified by Posner with the sound produced by a woman's high heeled shoes against the pavement) and enduring ones (epitomized, again in a very typical Posnerean way, by the prints that the woman's shoes may leave in clay, in particular if the latter is later dried). The transitory artefacts, in this sense, also have a material aspect, just as the lasting ones; they only have the particularity of developing in the time, which is why they cannot be accumulated without first being converted. Normally, it is Posner's transitory artefacts whose development in time causes them to seem somehow "less" material (which is of course nonsense but must be taken seriously in the Lifeworld). It is easy to understand that thinkers of the Enlightenment like Diderot and Lessing could conceive of language (which they tended to imagine in its spoken form) as a "more subtle material" than the picture that endures in time (at least until air is let into the prehistoric caverns or car exhaust is allowed to devastate the frescoes of a later time).

Strictly speaking, the sound sequence produced by high heels against the pavement, as well as many other transitory artefacts which have failed to retain Posner's attention, can of course be accumulated (as opposed to being converted into enduring artefacts, which is the case of the sound tape), in the form of the (typical) leg movements producing this sound, that is, as a mimic record, accumulated in the body, but still distinct from it, since the movements can be learnt and imitated, and even intentionally produced as signs of (traditional) femininity, or something of the kind. Posner's example of an enduring artefact is interesting in another way: the cast of prints left by the woman's high heels is an organism-independent record, just as the marks of a Roman soldier's sandals found in prehistoric caves, and the hand-prints on cave walls. Another case in point may very well be the so-called Berekhat Ram figure (250-280 000 BP), which, if it is not the likeness of a woman, as has been claimed with very little justification, could be the result of abrasion produced by regular movements indicating the intervention of a human agent (that is, "anthropogenic" movements). This suggests that the first organism-independent records are indexical, rather than iconic, in character. However, even if objects like these were independent objects already in prehistory, there is nothing to prove that they were perceived as signs, that is, as expressions which are seen to be distinct from their contents, before pictures were so 
perceived.

Harold Innes (1950) differentiates all cultures according as they emphasise more enduring storage media which are difficult to transport, such as stone tablets, or media which are less enduring, but easier to transport like the papyrus - in other words, according to the relative accent the cultures put on the aspect of accumulation and transport, in the sense of Lotman. In a similar way, Metz (1990) has claimed that a photograph, but not a film, could become a fetishist object, in the Freudian sense, precisely because the former has more of a material character. All cases considered by Innes are of course enduring artefacts, as is the photograph (while the case of the film is more complex); it is only that their capacities for accumulation and communication respectively are more or less emphasised. The distinctions established within cultural history by Innes thus only concern Donald's theoretic stage.

[Fig. 2.]

These reflections are only the beginning of what could become an intricate phenomenology of memory records or artefacts. It is impossible to take it further here. We can only make a few suggestions as to the different ways in which Donald's memory types relate to various kinds of embodiment (cf. Fig. 2.). Episodic memory is most clearly disembodied. It may refer to a bodily act, such as going in or out of a container-type object (such as, for instance, making love; cf. Sonesson 1989, forthcoming b), but it is unable to generalise this movement beyond a particular moment and place, and thus it does not give rise to any kind of independent embodiment. Mimetic memory still accumulates in the own body, but it only becomes such, to the extent that what is recorded in the body also exists elsewhere, in at least one other body, which supposes generalisation or, more exactly, typification, the creation of a type referring to different tokens instantiated in different bodies. Typification, in this sense, does not require the semiotic function, but is probably a prerequisite for it. Mythic memory (which I would prefer to call linguistic memory or perhaps, as Donald sometimes does, semantic memory) is different again: it has a separate existence, but, like some kind of real-world ectoplasm, is requires the collaborative effort of a least two consciousnesses (which no doubt have to be embodied) for this existence to be sustained. Transitory artefacts, as verbal language or (as Posner would have it) the sound of high-heeled shoes on the pavement, acquire a body only to the extent that a sender and a receiver agree roughly on what they are. Only theoretic memory has a distinct body of its own: it subsists independently of the presence of any embodied consciousness, because it is itself embodied. Of course, without anybody around to perceive it, organism-independent records are not of any use. Without any human beings present, they are really worse off than the famous acorn falling from a tree without anybody around to hear its sound. ${ }^{9}$ 
So the question now becomes: what is required for the body to become a depository of memories, that is, repeatable acts? And what is needed for these acts to become signs? None of these questions have any meaning, if we cannot give a better definition of typicality as well as sign function than those which are commonly offered.

\section{Signs standing out}

It is true of both the main traditions of semiotics, the Saussurean and the Peircean one, that they have never really offered any definition of the sign; and the same thing no doubt applies to the notion of representation in cognitive science. ${ }^{10}$ This goes a long way to explaining why many semioticians (such as Greimas, Eco, etc.) have rejected the sign, without much of an argument, and why the second generation of adepts to cognitive science now seems to be doing the same thing. When Peirceans and Saussureans quarrel over the presence of two or three entities in the sign, they never pause to ask themselves what kind of objects, defined by what type of features, are involved: but, clearly, before we know what we are counting, it makes no sense to start counting at all. The whole question becomes moot, if there is no reason to analyse meaning into two parts, as suggested by both contemporary cognitive scientists and old-time existentialists and Lebensphilosophen. So before we even ask ourselves whether the sign makes psychological and evolutionary sense, we have to be clear about what it is. This involves not only deciding the criteria for analysing a phenomenon of meaning into two separate parts, but also those allowing us to posit an asymmetrical relation between these parts: not only does the expression have to be separate from the content, but the former should stand for the latter, not the reverse (cf. Sonesson 1992a, b; 1993; 1994b; 2001a, b; 2003b, forthcoming a).

[Fig. 3.]

Before we can separate signs from other meanings, we have to spell out those criteria for something being a sign which are simply taken for granted, in both the Peircean and the Saussurean tradition. This can be done by combining what Husserl says about appresentation (something which is directly present but not thematic refers to something which is indirectly present but thematic) and what Piaget says about the semiotic function (there is a differentiation between the latter two instance, in the double sense, I take it, that they do not go over into each other in time and/or space, and that they are perceived to be of different nature; cf. Fig. 3.).

According to Piaget the semiotic function (which, in the early writings, was less adequately termed the symbolic function) is a capacity acquired by the child at an age of around 18 to 24 months, which enables him or her to imitate something or somebody outside the direct presence of the model, to use language, make drawings, play "symbolically", and 
have access to mental imagery and memory (a list in which Donald's mimetic skills come together with much later capacities). The common factor underlying all these phenomena, according to Piaget, is the ability to represent reality by means of a signifier which is distinct from the signified. Indeed, Piaget argues that the child's experience of meaning antedates the semiotic function, but that is does not then suppose a differentiation of signifier and signified in the sign (see Piaget 1945; 1967; 1970). In several of the passages in which he makes use of this notion of semiotic function, Piaget goes on to point out that "indices" and "signals" are possible long before the age of 18 months, but only because they do not suppose any differentiation between expression and content. The signifier of the index, Piaget says, is "an objective aspect of the signified"; thus, for instance, the visible extremity of an object which is almost entirely hidden from view is the signifier of the entire object for the baby, just as the tracks in the snow stand for the prey to the hunter. But when the child uses a pebble to signify candy, he is well aware of the difference between them, which implies, as Piaget tells us, "a differentiation, from the subject's own point of view, between the signifier and the signified".

Piaget is quite right in distinguishing the manifestation of the semiotic function from other ways of "connecting significations", to employ his own terms. Nevertheless, it is important to note that, while the signifier of the index is said to be an objective aspect of the signified, we are told that in the sign and the "symbol" (i.e. in Piaget's terminology, the conventional and the motivated variant of the semiotic function, respectively) expression and content are differentiated from the point of view of the subject. Curiously, this distinction between the subjective and objective points of view is something Piaget seems to forget in the following. We can, however, imagine this same child that in Piaget's example uses a pebble to stand for a piece of candy having recourse instead to a feather in order to represent a bird, or employ a pebble to stand for a rock, without therefore confusing the part and the whole: then the child would be employing a feature, which is objectively a part of the bird, or the rock, while differentiating the former from the latter from his point of view. Only then would he be using an index, in the sense in which this term is employed in semiotics, that is, in (what at least this semiotician takes to be) the Peircean sense of the term.

The hunter, on the other hand, who identifies the animal by means of the tracks, and then employs them to find out which direction the animal has taken, and who does this in order to catch the animal, does not, in his construal of the sign, confuse the tracks with the animal itself, in which case he would be satisfied with the former. Both the child in our example and the hunter are using indices, or indexical signs, where the "real" connection is transformed into a differentiation in the sign. According to some current conceptions, this would not necessarily be true in prehistory: chimpanzees and early humans appear to be unable to make 
use of tracks in their hunting behaviour, if cognitive archaeology is to be trusted (Mithen 1996, 73ff). ${ }^{11}$

On the other hand, the child and the adult will fail to differentiate the perceptual adumbration in which he has access to the object from the object itself; indeed, they will identify them, at least until they change their perspective on the object by approaching it from another vantage point. And at least the adult will consider a branch jutting out behind a wall as something which is non-differentiated from the tree, to use Piaget's example, in the rather different sense of being a proper part of it. In the Peircean sense an index is a sign, the relata of which are connected, independently of the sign function, by contiguity or by that kind of relation which obtains between a part and the whole (henceforth termed factorality). But of course contiguity and factorality are present everywhere in the perceptual world without as yet forming signs: we will say, in that case, that they are mere indexicalities. Perception is perfused with indexicality. Each time two objects are perceived together in space, there is contiguity; and each time something is seen to be a part of something else, or to be a whole made up of many parts, there is factorality. Two items present together only become a sign, however, to the extent that one of them, identified as the expression, is directly perceived but not in focus, and the other one, the content, is indirectly perceived while at the same time being the focus of the relation (cf. Husserl 1939; Luckmann 1980).

[Fig. 4.]

An index, then, must be understood as indexicality (an indexical relation or ground, to use an old Peircean term) plus the sign function. Analogously, the perception of similarities (which is an iconic ground) will give rise to an icon only when it is combined with the sign function. I therefore cannot agree with Deacon (1997, 76ff) when he claims that camouflage in the animal world such as the moth's wings being seen by the bird as "just more tree" are essentially of the same kind as those "typical cases" of iconicity we are accustomed to call pictures. As always, there are passages in Peirce's work which may be taken in different ways, but it makes more systematic and evolutionary sense to look upon iconicity and indexicality as being only potentials for something being a sign which still have to be “embodied", as Peirce $(1998,291)$ more clearly says about a sign type according to another division, the qualisign which "cannot actually act as a sign until it is embodied; but its embodiment has nothing to do with its character as a sign" (cf. Sonesson 2003a and Fig. 4).

Something like Husserl's criteria are required, but perhaps not sufficient, in order to separate the sign function from other dyadic relations between (more or less) differentiated members. It is possible, no doubt, to conceive of the sign as some kind of mapping between "mental spaces", as suggested by Fauconnier (1994, \& Sweetser 1996), but this is not of 
much use as long as we have no criteria for separating the sign from all other instances of such mappings listed by Fauconnier, such as counterfactuals, analogy, metaphors, metonymy, propositional attitudes, modalities, pragmatic terms, frames, models, and so on. This is of course not to deny that some valuable generalisations may be stated at this level.

While the introduction of the notion of differentiation is a substantial accomplishment on the part of Piaget, he unfortunately never spells out its import. As I have mentioned above, he defines it in terms of the subject's point of view, but then uses examples in which the disconnection already exists objectively. The sense of objectivity and subjectivity employed here should of course be related to the common sense world (that is, the Lifeworld) in which human beings stake out their life. Indeed, what Piaget is concerned with is precisely the "construction", in his terms, by the child of the common sense world. Once this edifice is finished, the common sense world disjoins that which is subjective (which does not mean particular to one individual, but may very well be the "world view" of a particular language, the way of segmenting reality opposing pictures to language generally, etc.) from that which is objective (which is, strictly speaking, the subjectivity common to human beings). But, in his later reasoning and examples, Piaget seems to identify differentiation from the subject's point of view with conventional, or arbitrary, signs, in the Saussurean sense. This will not do, for already "symbols", in the Saussurean sense, are differentiated in this way. ${ }^{12}$

Nor should differentiation be identified with displacement as defined by Hockett, which (rightly, no doubt) appears as one of the "design features" of language in most introductory textbooks. ${ }^{13}$ As in the case of the tracks left by the hunted animal, displacement may be a consequence of differentiation. But differentiation only comes on its own when the sign is in presence of its referent, for then it allows us to construe reality in different ways ("subjectively", as Piaget would have said), picking out that which is relevant, and ignoring, or downplaying other features.

We must be careful not to confuse different relationships involving the sign. Differentiation, in Piaget's sense, must pertain to the signifier and the signified, which are always equally present in the here and now of the sign user, since they are mental (or, more exactly, intersubjective) entities. To the hunter, both the signifier and the signified of the tracks are present here on the ground (or, to be precise, in his perception of the ground). But the signified contains the information that it is itself only part of a larger whole (or rather something once contiguous to a larger whole) which was present here at an earlier time, but which is now elsewhere, more precisely in the direction indicated by the tracks. And the displacement, in Hocket's sense, has taken place between that signified whole and the real animal which is now present somewhere else. 
When the sign, whether it is a stretch of discourse, a picture, or an animal track, is present along with the referent, however, the signified allows us to refocus the referent, in other words, to present it in a particular perspective. For this requires independence: that is to say, a body of its own.

\section{Focusing on typicality}

Types and regularities are characteristic features of the Lifeworld, also known as the "world taken for granted", as described by Husserl and his followers such as Alfred Schütz and Aron Gurwitsch, as well as of the world of "ecological physics", as defined by James Gibson (cf. Sonesson 1989, 1994a, b; 1996; 1997). The "commens" characterised by Peirce $(1998,478)$ would seem to be a similar domain of shared assumptions. Every particular thing encountered in the Lifeworld is referred to a general type. According to Schütz, other people, apart from family members and close friends, are almost exclusively defined by the type to which they are ascribed, and we expect them to behave accordingly. Closely related to the typifications are the regularities which obtain in the Lifeworld, or, as Husserl's says, "the typical way in which things tend to behave". This is the kind of principles tentatively set up which are at the foundation of Peircean abductions; indeed, Peirce, in a parallel fashion, refers to the "habits" of things. Many of the "laws of ecological physics", formulated by Gibson (1982, 217ff), and which are defied by magic, are also such "regularities /that/ are implicitly known": that substantial objects tend to persist, that major surfaces are nearly permanent with respect to layout, but that animate objects change as they grow or move; that some objects, like the bud and the pupa transform, but that no object is converted into an object that we would call entirely different, as a frog into a prince; that no substantial object can come into existence except from another substance; etc. (cf. Sonesson 1992a; 2000; 2001a).

It has been suggested (notably by Smith \& Varzi 1999) that the Lifeworld is simply the niche, in the sense of (non-Gibsonean) ecology, in which the animal known as the human being stakes out his life (cf. Sonesson 2001a, 99). The niche, then, in this sense, is the environment as defined by and for the specific animal inhabiting it. In Husserlean language, the niche is subjective-relative - relative to the particular species. The precursor of the niche, understood in this way, is the notion of Umwelt introduced by von Uexküll, which is today the defining concept of the speciality known as biosemiotics. But this parallel is true, I submit, only to the extent that we treat the Lifeworld as mere background, without attending to the thematic adumbrations in which meaning comes to life and, among other things, is transformed to signs.

Uexküll's notion of meaning centres on the environment, the Umwelt, which is differently defined for each organism. As opposed to an objectively described ambient world, the 
Umwelt is characterised for a given subject, it terms of the features which it perceives (Merkwelt) and the features which is impressed on it (Wirkwelt), which together form a functional circle (Funktionskreis). According to a by now classical example, the tick hangs motionless on a bush branch until it perceives the smell of butyric acid emitted by the skin glands of a mammal (Merkzeichen), which sends a message to its legs to let go (Wirkzeichen), so that it drops onto the mammal's body. This starts a new cycle, because the tactile cue of hitting the mammal's hair incites the tick to move around in order to find its host's skin. Finally, a third circle is initiated when the heat of the mammal's skin triggers the boring response in order to drink the blood of its host. Together, these different circles consisting of perceptual and operational cue bearers make up the interdependent wholes of the subject, corresponding to the organism, and the Umwelt, which is the world as it is defined for the subject in question.

Biosemioticians tend to take this model, immensely enlightening as it is in itself, and simply project onto it the sign conception attributed to Peirce. To the extent that this is feasible, however, the Peircean notion of sign is not really about the semiotic function, but involves some more general notion of meaning. Not only is there no distinction between expression and content to the tick; there is no separation of sign and reality. The butyric acid, together with the hairiness and the warmth of the blood, simply is the mammal from point of view of the tick. ${ }^{14}$ This is no doubt the reason, never really spelled out, why Ernst Cassirer (1942, 29ff; 1945, 23ff), who was probably the first thinker outside of biology to take Uexküll's ideas seriously, never acknowledges Uexküll's conception to be, in the latter's own words "a theory of meaning" (though he says it involves "mediation"). For my part, I would prefer to accept Uexküll's description, while denying that the theory is involved with signs.

It is useful to distinguish relevance from filtering, although they have something in common: the picking up a limited set of features from the totality of the environment (cf. Sonesson 1988; 2003a). However, relevance, strictly speaking, does not exclude anything: it merely places some portions of the environment in the background, ready to serve for other purposes. Thus, in the case of language, properties which are not relevant for determining the meaning of the sentence, still may serve to inform about the dialect, or even identify the person speaking (Hjelmslev's “connotational language”; cf. Sonesson 1989). In contrast, filtering simply crosses out that which is not let through the filtering device.

If the Umwelt is an organised network of filters, the Lebenswelt is a similarly organised network of relevancies or themes. It might therefore be said that what most perspicuously differentiates the tick from the human being (without prejudging for the moment on the question where the exact border is to be placed) is the structure of the field of consciousness: 
in Gurwitsch's $(1957 ; 1964 ; 1985)$ terms, human consciousness is made up of a theme which is the centre of attention, a thematic field around it consisting of items which are connected to the present theme by means of intrinsic links permitting it to be transformed into a theme in its own right, as well as other items present "at the margin" at the same time, without having any other than temporal relations to the theme and its field. ${ }^{15}$ The tick of course has access neither to the thematic field nor to the margin. Not only is there no way for the tick to "go on from here" (the Husserlean etcetera principle), its experience of the here and now is also very limited. In other words, there is no real "immediate object" to the tick, not only because it is not opposed to a future more extensive "dynamical object", but also because even in the here and know, what is immediately experienced does not appear as a thematic structuring, or perspective, on such a dynamical object. ${ }^{16}$

As Husserl and Gibson have insisted, in the human Lifeworld, we are alternatively confronted with the-cat-from-one-side, the-cat-from-above, the-cat-from-the-front, etc., but what we really see is all the time the same invariant cat. The tick smells the same invariant butyric acid, period. In the world of the tick, there are no signs, as distinct from the world itself. Differentiation has not even started. In other words, signification has not acquired a "body" of its own. ${ }^{17}$

\section{Beyond the camouflage, the portrait}

James Gibson (1978) has emphasised the dissimilarity of the picture from a real-world scene, thus showing the numerous experiments using pictorial stimuli to study normal perception to be seriously misguided. To both Husserl and Gibson, normal perception gives direct access to reality; in contrast, Gibson claims pictures represent a kind of indirect perception, and Husserl (1980) tells us that they are "perceptually imagined" (cf. Sonesson 1989,III.3.6). To perceive surfaces is a very different thing from perceiving marks on surfaces, Gibson (1980) maintains. In fact, the perception of surfaces, of their layout, and of the transformations to which the latter are subjected, is essential to the life of all animal species, but the markings on these surfaces have only gained importance to man, notably in the form of pictures. The marks, produced by what Gibson calls the graphic act, can be deposits, traces, lines, or shadows projected on the surface (Gibson 1980, xii; 1978, 229). Surfaces have the kind of meaning which Gibson elsewhere calls "affordances"; the markings on surfaces, however, have "referential meaning". Without discussing the exact import which should be given to the term "affordance", we may safely conclude that "referential meaning" is a property of what we have called the semiotic function. That is, surfaces do not stand for other surfaces, but the markings on surfaces may possibly do so.

To Gibson, then, the picture is a surface among other surfaces before becoming a sign. 
Gibson $(1978,231)$ observes that, besides conveying the invariants for the layout of the pictured surfaces, the picture must also contain the invariants of the surface which is doing the picturing: those of the sheet of paper, the canvas, etc., as well as those of the frame, the glass, and so on. Although Gibson does not use the term, he clearly implies that the picture is a sign, in the sense of being as a surface which, on being perceived, brings into awareness something besides itself. Gibson never specifies what he means when he claims that surfaces are seen to stand for something else by human beings only, as opposed to animals and children. If he means to suggest that surfaces can never be taken to be something else than surfaces by animals and children he is clearly wrong: we know that even doves may react in the same way to a picture as to that which is depicted (cf. Sonesson 1989,III.3.1). The difficulty, clearly, consists in seeing, at the same time, both the surface and the thing depicted. In other words, it consist in making a differentiation: in telling the "body" of the sign apart from the "body" of the object to which it alludes.

In contrast, when discussing "the reference problem", Terry Deacon (1997, 59ff) opposes "the way words refer to things" (to which he assimilates rules of etiquette and games) to "a vervet monkey alarm call, a laugh, or a portrait". No matter what features we attend to, the portrait, in my view, just as any other picture, undoubtedly refers in a way much more similar to words, than does either a laugh or a rule of etiquette. Indeed, Deacon would seem to agree with this. Later on in the text, he talks about "external symbolization in the form of paintings, carvings, or just highly conventional doodlings" (p. 365f) which are "the first concrete evidence of the storage of such symbolic information outside of the human brain" (p. 374; my italics). ${ }^{18}$ From a Peircean point of view, Deacon is quite right in searching for a "basic sense" of iconicity beyond "the way we typically use the term", but what he comes up with is both too much and too little. Deacon $(1997,74 \mathrm{ff})$ suggests that iconicity is the fact of there being no distinction: the perception of the same "stuff" over and over again. It is, he maintains, like camouflage: the moth's wings being seen by the bird as "just more tree". He goes on to suggest that iconicity is recognition, that is, the identification of a category, and even "stimulus generalisation" (p. 77ff). Then he claims that "typical cases" such as pictures are essentially of the same kind: what makes pictures into icons is "the facet or stage that is the same for a sketch and the face it portrays" (p. 76f).

There is no space here to discuss the complex issue of interpreting the Peircean category of Firstness, of which the icon is an instance (cf. Sonesson 1998a,b; 2000; 2001a, 2003a). However, it is entirely clear from Peirce's writings that Firstness supposes a (potential) world deprived of relations (which first are introduced with Secondness): thus, it can never correspond to recognition, stimulus generalisation, or category membership, much less to the 
picture sign, which all suppose relationships. However, to the extent that Deacon intends to identify iconicity with what is known in psychology as "categorical perception" he may be right: the perception of something as being identical as long is it appears between a lower and a higher threshold of some property subject to variation. In this respect, iconicity, to Deacon, would be equivalent to what we have above called the filtering function. All objects emitting butyric acid are identical to the tick. Thus, camouflage, to the extent that it is never discovered to be camouflage, the stem, to the extent that its identity is not the product of an act of comparison, and stimulus generalisation, as long as it never becomes conscious as such, could be seen as simple iconicities, that is, repertories of properties.

Recognition, however, must already be an iconic ground. In one of his well-known definitions of the sign, a term which he here, as so often, uses to mean the sign-vehicle, Peirce (1931-58, II, 228) describes it as something which "stands for that object not in all respects, but in reference to a sort of idea, which I have sometimes called the ground of the representation" (my italics; cf. Fig. 1). Some commentators have claimed that Peirce is here talking about some properties of the expression, whereas others favour the content. In fact, however, the ground must concern the relation between them. Such an interpretation seems to be born out by Peirce's claim that the concept of "ground" is indispensable, "because we cannot comprehend an agreement of two things, except as an agreement in some respect." (I.551). In another passage, Peirce himself identifies "ground" with "abstraction" exemplifying it with the blackness of two black things (I.293). It therefore seems that the term ground must stand for those properties of the two things entering into the sign function by means of which they get connected, i.e. both some properties of the thing serving as expression and some properties of the thing serving as content. In case of the weathercock, for instance, which serves to indicate the direction of the wind, the content ground merely consists in this direction, to the exclusion of all other properties of the wind, and its expression ground is only those properties which makes it turn in the direction of the wind, not, for instance, the fact of its being made of iron and resembling a cock (the latter is a property by means of which it enters an iconic ground, different from the indexical ground making it signify the wind). If so, the ground is really a principle of relevance, or, as a Saussurean would say, the "form" connecting expression and content: that which must necessarily be present in the expression for it to be related to a particular content rather than another, and vice-versa (cf. Sonesson 1989, III.1).

However, since Peirce always insists that the properties of iconicity and indexicality pertain to objects independently of their entering into a sign relation, we should be able to conceive of iconic and indexical grounds as having other functions; thus, for instance, iconic 
grounds may be used to create categories of things having some properties in common (beyond those being picked out by the automatic functional circle intrinsic to our Umwelt); and indexical grounds may form the basis for putting things together with the purpose or creating a whole. Thanks to iconic grounds, we recognise things as being of the same general category; and because of indexical grounds, we discover parts of bigger wholes or relations of contextuality (cf. Fig. 4.).

To see camouflage as camouflage is of course to deprive it of its functionality: it is not meant to be discovered as such. The capacity for doing so is useful for the biologist, as it is of course for the potential victims or predators of the animal using the camouflage. The case of the picture is quite different. It only functions as a picture when it is seen as a picture. This is what is meant by the picture being a sign. It is not a stand-in for that which it represents: like verbal language, it is a way of making the absent thing present as seen from a particular point of view, that is, thematically adumbrated. This is why it needs a body of its own.

Iconicity and sign character are certainly independent, at Peirce claims, because there are iconic grounds which are not signs, and signs which are not icons (but indices, symbols, or some combination). In another sense, however, the iconicity of signs is not something which can be considered apart from their sign character: as I have suggested elsewhere (Sonesson 1993; 1994a, b; 2001a), the iconicity of iconic signs is either a consequence of their being signs or a prerequisite for it. A primary iconic sign is a sign in the case of which the perception of a similarity between an expression $\mathrm{E}$ and a content $\mathrm{C}$ is at least a partial reason for $\mathrm{E}$ being taken to be the expression of a sign the content of which is $\mathrm{C}$. That is, iconicity is really the motivation, or rather, one of the motivations, for positing the sign function. A secondary iconic sign, on the other hand, is a sign in the case of which our knowledge that $\mathrm{E}$ is the expression of a sign the content of which is $\mathrm{C}$, in some particular system of interpretation, is at least a partial reason for perceiving the similarity of $\mathrm{E}$ and $\mathrm{C}$. Here, then, it is the sign relation which partially motivates the relationship of iconicity.

Pictures are clearly primary iconic signs. As psychological and ethnological studies have shown (cf. Sonesson 1989; 1993; 1994a, b; 2001a), any human being beyond 19 months of age will immediately recognise a picture as a picture of a certain object, to the extent that he has had earlier experience with the object in question, not, however, with the picture. Other iconic signs are secondary, in this sense. A car, which is not a sign on the street, becomes a sign at a car exhibition, as does Man Ray's iron in a museum. We have to know the showcase convention to understand that the tin can in the shop-window stands for many other objects of the same category; we need to be familiar with the art exhibition convention to realise that each object merely signifies itself; and we are able to understand that the tailor's swatch is a 
sign of its pattern and colour, but not of its shape, only if we have learnt the convention associated with the swatch. This also applies to many gestures and to the kind of scribbles which Arnheim $(1969,92 \mathrm{f})$ calls "droodles" which are different from pictures in requiring a key, as Carraci's mason behind a wall (cf. Fig. 5b), or in "Olive dropping into martini glass or Close-up of girl in scanty bathing suit" (cf. Fig. 5a).

When Man Ray makes a picture of a billiard table, we need no convention to recognise what it depicts. However, if Sherrie Levine's (real, three-dimensional) billiard table is to represent Man Ray's picture, there must be a label inverting the hierarchy of prominence of the Lifeworld. This shows that among the properties determining the probability of an object functioning as the expression of an iconic sign is to be found two-dimensionality rather than the opposite. In other words, it is easier to see a two-dimensional object as a sign for a threedimensional one than the reverse. Since the inception of modernism, and particularly in the phase known as postmodernism, the sign function of pictures has been at the centre of interest: it is thus not surprising that artists, such as Levine, should employ themselves to inverse the normal Lifeworld hierarchy, which makes two-dimensional objects stand for three-dimensional ones, rather than the reverse. But similar things also happen in the world of everyday life: according to an anecdote told me by friends, a Mexican woman visiting Sweden for the first time thought this country to be full of "Barbies", which amounts to the same inversion, because, building on her particular Lifeworld experience, she took real, animate, persons as being, at least for the duration of a speech act, representations of assembly-line fabricated objects, made of inanimate matter, i.e. dolls.

All this goes to show that tertiary embodiment is not independent of the primary one: iconicity is primary as long as it reproduces the conditions of our own body. The problem with interstellar messages such as the Pioneer plaque showing pictures of human beings is not only that extraterrestrial intelligent beings might not have bodies similar to ours; it is, more generally, that like many terrestrial animals, they may not consider surfaces to be able to stand for three-dimensional objects, nor understand the equivalence of marks on a surface to edges of three-dimensional bodies. In this sense, primary embodiment remains the condition of access also to tertiary embodied objects.

\section{Conclusions}

Taking my point of departure in classical embodiment theories stemming from the phenomenological tradition, I have discussed tertiary embodiment, characteristic of certain types of signs, such as pictures and writing, as a particular stage of development in the phylogeny and ontogeny of human beings. In so doing, I have singled out the sign function as an indirect access to signification in opposition to the more direct experience of signification 
in the Lifeworld, also known as the world of ecological physics. Indeed, another purpose of the essay has been to outline the way in which the semiotic function, the general faculty for conceiving signs, emerges out of one kind of embodiment and constitutes a requirement for attaining another one.

\section{References}

Arnheim, Rudolf, (1966). Towards a psychology of art. London: Faber \& Faber.

Cassirer, Ernst, (1942). Zur Logik der Kulturwissenschaften. Göteborg: Elanders.

- (1945). An essay on man. New Haven: Yale University Press.

- (1957). The Philosophy of symbolic forms. III. The phenomenology of knowledge.

Translated by Ralph Mannheim. New Haven: Yale University Press.

Deacon, Terry, (1997). The Symbolic Species: The Co-Evolution of Language and the Brain. New York: Norton.

- (2003). Universal grammar and semiotic constraints. In Christiansen, Morton H, \& Simon

Kirby (eds)., Language evolution, 111-139. Oxford: Oxford University Press.

Deely, John, (1982). Introducing Semiotic. Its history and doctrine. Bloomington: Indiana

University Press.

Donald, Merlin, (1991) Origins of the Modern Mind. Three Stages in the Evolution of Culture and Cognition, Cambridge, Mass.: Harvard University Press.

- (2001). A Mind So Rare. The Evolution of Human Consciousness. New York: Norton.

Edelmann, Gerald, (1992). Bright Air, brilliant fire. On the matter of the mind. London: Penguin Books.

Edelmann, Gerald, \& Tonini, Guilio, (2000). A universe of consciousness. New York: Basic Books

Fauconnier, Gilles, (1994). Mental spaces. New York : Cambridge University Press. Second edition.

Fauconnier, Gilles, \& Sweetser, Eve (eds), (1996). Spaces, Worlds, and Grammar. Chicago \& London : The University of Chicago Press.

Gibson, James, (1978). The ecological approach to visual perception of pictures, Leonardo, 4:2: 227-235.

- (1980). A prefatory essay on the perception of surfaces versus the perception of markings on a surface, in Hagen, Margaret, ed., The perception of pictures, Volume I: Alberti's window. xi-xvii. New York: Academic Press.

- (1982). Reasons for realism. Reed, Edward, \& Jones, Rebecca, (eds). Hillsdale New Jersey: Lawrence Eearlbaum Ass. 
Gurwitsch, Aron, (1957). Théorie du champ de la conscience. Bruges: Desclée de Brouver. - (1964). The field of consciousness. Pittsburgh: Duquesne University Press.

- (1966). Studies in Phenomenology and Psychology. Evanston: Northwestern University Press.

- (1974). Phenomenology and the theory of science. Evanston: Northwestern University Press.

- (1979) Human encounters in the social world. Pittsburgh: Duquesne University Press

- (1985). Marginal consciousness. Athens, Ohio: Ohio University Press.

Husserl, Edmund, (1939). Erfahrung und Urteil. Prag: Academia Verlagsbuchhandlung.

- (1962a). Die Krisis der europäischen Wissenschaften und die transzendentale

Phänomenologie. Husserliana VI. The Hague: Nijhoff.

- (1962b). Phänomenologische Psychologie. Husserliana IX. The Hague: Nijhoff.

- (1980). Phantasie, Bildbewusstsein, Erinnerung. Husserliana XXIII. The Hague: Nijhoff.

Innes, Harold, (1950). Empire and communication. Toronto: University of Toronto Press, 1950. 2nd ed. 1972.

Ivins, William M., (1953). Prints and visual communication. Cambridge, Mass., Harvard University Press.

Johnson, Mark, (1987). The body in the mind. Chicago \& London: University of Chicago Press.

Lakoff, George \& Mark Johnson, (1999). Philosophy in the flesh. New York: Basic books.

Lotman, J.M \& Uspenskij, B.A., Ivanov, V.V., Toporov, V.N., \& Pjatigorskij, A.M., (1975).

Thesis on the semiotic study of culture. Lisse: The Peter de Ridder Press.

Luckman, Thomas, (1980). Lebenswelt und Geschichte. Paderborn: Schöning.

Masuda, Y. , (1980). Information society as post-industrial society. Washington, D.C., World future society.

Metz, Christian, (1990). Photograph and fetish, in Sqioers. Carol, ed., The critical image.

Essays on contemporary photography, 155-164. Seattle: Bay Press.

Mithen, Steven, (1996). The Prehistory of the Mind. London: Thames \& Hudson.

Piaget, Jean, (1945). La formation du symbole chez l'enfant. Neuchatel: Delachaux \& Niestlé.

Third edition 1967.

- (1967). La psychologie de l'intelligence. Paris: Armand Colin.

- (1970). Epistémologie des sciences de l'homme. Paris: Gallimard.

Peirce, Charles Sanders, (1931-58). Collected Papers I-VIII. Hartshorne, C, Weiss, P, \&

Burks, A, (eds.). Cambridge, MA: Harvard University Press.

- (1998). The Essential Peirce, volume II. Ed. By the Peirce Edition Project. Bloomington 
and Indianapolis: Indiana University Press.

Posner, Roland, (1989). What is culture? Toward a semiotic explication of anthropological concepts, in The Nature of Culture. Koch, Walter, ed., 240-295. Bochum. Brochmeyer. Schütz, Alfred, (1932). Der sinnhafte Aufbau der sozialen Welt. Springer, Vienna 1932. New editiion Suhrkamp, Frankfurt/M.1974.

- (1967). Collected papers I: The problem of social reality. Nijhoff, The Hague.

Smith, Barry, \& Varzi, Achille, (1999). The niche, in Noûs, 33:2, 198-222.

Sonesson, Göran, (1988). Methods and models in pictorial semiotics. Semiotics project: Lund University.

- (1989). Pictorial concepts. Inquiries into the semiotic heritage and its relevance for the analysis of the visual world. Lund: Aris/Lund University Press.

- (1992a). Bildbetydelser. Inledning till bildsemiotiken som vetenskap. Lund:

Studentlitteratur.

- (1992b). The semiotic function and the genesis of pictorial meaning. In Tarasti, Eero (ed.), Center/Periphery in representations and institutions. Proceedings from the Conference of The International Semiotics Institute, Imatra, Finland, July 16-21, 1990., 211-156. Imatra: Acta Semiotica Fennica.

- (1993). Pictorial semiotics, Gestalt psychology, and the ecology of perception. In Semiotica 99: 3/4, 319-399.

- (1994a). Prolegomena to the semiotic analysis of prehistoric visual displays. In Semiotica, 100: 3/, 267-332. 47-64.

- (1994b). Sémiotique visuelle et écologie sémiotique, in RSSI, 14, 1-2, printemps 1994, pp. 31-48. 47-64.

- (1995). On pictorality. The impact of the perceptual model in the development of visual semiotics. In Sebeok, Th., \& Umiker-Sebeok, J. (eds), .The semiotic web 1992/93: Advances in visual semiotics, 67-108. Mouton de Gruyter, Berlin \& New York.

- (1996). An essay concerning images. From rhetoric to semiotics by way of ecological physics. In Semiotica, 109-1/2, 41-140.

- (1997). The ecological foundations of iconicity, in Rauch, Irmgard, \& Carr, Gerald F., (eds.), Semiotics Around the World: Synthesis in Diversity. Proceedings of the Fifth International Congress of the IASS, Berkeley, June 12-18, 1994. 739-742. Berlin \& New York: Mouton de Gruyter.

- (1998a). /entries/, in Encyclopaedia of Semiotics. Bouissac, Paul, ed., New York \& London: Oxford University Press.

- (1998b). That there are many kinds of pictorial signs, Visio, 3, 1, 33-54. 
- (2000). Iconicity in the ecology of semiosis, In Troels Deng Johansson, Martin Skov \& Berit Brogaard (eds.), Iconicit y - A Fundamental Problem in Semioti, 59-80. Aarhus: NSU Press.

- (2001a). From Semiosis to Ecology. On the theory of iconicity and its consequences for the ontology of the Lifeworld. In Quinn, Andrew W., (ed.), Cultural cognition and space Cognition/Cognition culturelle et cognition spatiale. VISIO, 6: 2-3: 85-110.

- (2001b). De l'iconicité de l'image à l'iconicité des gestes, Actes du congrès ORAGE 2001 ORAlité et Gestualité, Aix-en-Provence, Juin 18-22, 2001. Paris : L'Harmattan.

- (2003a). The Symbolic Species revisited. Considerations on the semiotic turn in cognitive science and biology SGBWP3. Working Papers of the Project "Language, gesture, and pictures from the point of view of semiotic development", Lund University, Lund.

- (2003b). Why the mirror is a sign - and why the television picture is no mirror. Two episodes in the critique of the iconicity critique. In Proceedings of the 5th International Interdisciplinary Symposium of the Austrian Society for Semiotic Studies "Picture Language - Visualization - Diagrammatics: Iconicity/Das 5. Wiener Symposium 'Bildsprache - Visualisierung - Diagrammati": Ikonizität, November 2002, published as S. European Journal for semiotic studies, volume 15:2-4, 2003, pp. 217-232.

- (Forthcoming a). From Iconicity to Pictorality. A view from ecological semiotics. To appear in VISIO: thematic issue: Iconicity revisited/Iconicité revisité, Sonesson, Göran (ed).

- (Forthcoming b) The signs of the body and the body of signs. From ecology to semiosis in the theory of embodiment. In Zlatev, Jordan, Ziemke, Tom, \& Frank, Roslyn, (eds.), Body, language, and mind. Berlin \& New York: Mouton de Gruyter.

Spiegel, John \& Machotka, Pavel, (1974). Messages of the body. New York: The Free Press. Tomasello, Michael, (1999). The Cultural Origins of Human Cognition. Cambridge, MA: Harvard University Press.

Tomasello, Michael, Carpenter, Malinda, Call, Joseph, Behne, Tanya, \& Moll, Henrike, (In press). Understanding and sharing intentions: the origins of cultural cognition. In Behavioral and Brain Sciences, in press 2004.

Varela, Francisco., Thompson, Evan and Eleanor Rosch, (1991). The embodied mind. Cognitive science and human experience. Cambridge, Mass.: MIT Press.

White, Randall, (2000). Prehistoric art. New York: Harry N. Abrahams, Inc. Zlatev, Jordan, (2002). Mimesis: The "missing link" between signals and symbols in phylogeny and ontogeny. In A. Pajunen (ed.), Mimesis, Sign and the Evolution of Language (pp. 93-122). Turku: University of Turku Press. 


\section{$-(2003)$. Meaning $=$ Life $(+$ Culture $)$. An outline of a unified biocultural theory of meaning.}

Evolution of communication 4:2, 253-296.

1 Elsewhere (Sonesson 1989: 26ff), I have opposed, in this sense, the qualitative reduction to the more familiar quantitative one, characteristic of the traditional natural sciences. There are similarities, but also differences, to the series of "reductions" distinguished by Husserl: the phenomenological and eidetic reductions, notably.

${ }^{2}$ In terms familiar to contemporary embodiments theorists, the body/mind division is one of the most ubiquitous metaphors resulting from our most generally harboured "image schemes".

${ }^{3}$ Strictly speaking, this is not the problem of our own body, nor of the other, but the more general one of the external world, as pointed out by Gurwitsch (1979: 26f): but it is quite sufficient for us to note that it also applies to the body.

${ }^{4}$ But, contrary to those of Husserl, Peirce's investigations tend to manifest too much of what the Enlightenment philosophers called "l'esprit du système", i.e. the tendency to put anything discovered into the same categorical framework.

${ }^{5}$ Much of the present discussion is based on my work within the project "Language, gesture, and picture from the point of view of semiotic development", which is a collaborative effort between the department of semiotics, the department of linguistics, and the department of cognitive science at the University of Lund.

${ }^{6}$ On some other problems with the mimetic stage, cf. Zlatev 2002, 2003.

7 This is of course what is known, mainly in Marxist literature, as the process of alienation. As shown by Cassirer (1942: 113ff), this process, far from being only a "tragedy of culture", is the prerequisite for all culture.

${ }^{8}$ They can, however, be preserved as the capacity for reproducing them, that is, as the sequences of repeatable actions, which is an instance of Donald's mimetic memory.

${ }^{9}$ In fact, as I have argued in my critique of the critique of iconicity (Sonesson 1989, 1995, 1997, 1998a, b; 2000, $2001 \mathrm{~b}$, forthcoming a), for at least pictures to be perceived as such, not only the presence of a perceiver is required, but one who from the start makes some particular presuppositions about the hierarchy of things in the Lifeworld. See section 5 below!

${ }^{10}$ A more interesting interpretation of Peirce, however, may be that he was not really interested in the sign in our sense. For an analyses of this conception, see Sonesson $2003 \mathrm{~b}$, forthcoming b

${ }^{11}$ Actually, Mithen's examples suggest that apes are able to interpret auditive signs of the hunted animals, but will not even recognise the animal itself if presented with it visually, which suggest indexicality is not involved at all in this distinction. Indeed, many animals "lower" on the evolutionary scale are obviously able to interpret traces. According to this conception, the development of "art", i.e. picture signs, is an even later accomplishment of human prehistory (Mithen 1996: 150ff).

12 Other valid criticism may be levelled against Piaget, as discussed in Sonesson 1992b: the point that meaning emerges ontogenetically well before the attainment of the semiotic function (as expressed notably by

Trevarthen) is essential to the following argument. The observation, made experimentally by Gardner \& al., that the semiotic function is not attained in different media, and in different respects, at the same age, is important, but has nothing to do with the functional definition of this stage of development.

${ }^{13}$ And it has nothing to do with Hjelmslev's criteria for something being a sign, the possibility of separating expression and content into smaller parts independently. See Sonesson 1992a

${ }^{14}$ In Peircean terms, there is of course no distinction between the immediate and the dynamic object, but there is not even any difference between representamen, object, and interpretant. A close analyses of the use to which the Peircean terms are put by biosemioticians clearly reveals that they are really taken about what we will refer to below as filtering. See section 4 below and see Sonesson $2003 \mathrm{~b}$, forthcoming b

${ }^{15}$ Gurwitsch is right, I believe, in suggesting that this thematic structure translates to language (and no doubt also to other semiotic resources), as most clearly illustrated in the transposition of the functioning of pronouns 
from the perceptual world to discourse (cf. Gurwitsch 1985); it is unfortunate, however, that he fails to attend to the difference in structuring occasioned by the semiotic function.

${ }^{16}$ Cf. the discussion of attention by Tomasello 1999; \& Carpenter, Call, Behne, \& Moll, in press.

${ }^{17}$ It might be noted that the distinction I make here is parallel to my critique of the pictorial semiotics inaugurated by Roland Barthes, which I have shown to be only concerned with the things depicted (the referents), not the way in which these things appear in the picture (that is, the perspective in the wide sense of the term), nor the signifier as such (colour sports arranged in a particular way on a plane surface). Cf. Sonesson 1989.

${ }^{18}$ The passage quoted introduces a section which is concerned to show that there is more to the purported difference than conventionality. So perhaps Deacon would say that etiquette, just as language, is part of a system, whereas neither laughs or pictures are. But this only shows that his terms and his criteria are unclear. 


\section{Embodiment in phylogeny and ontogeny}

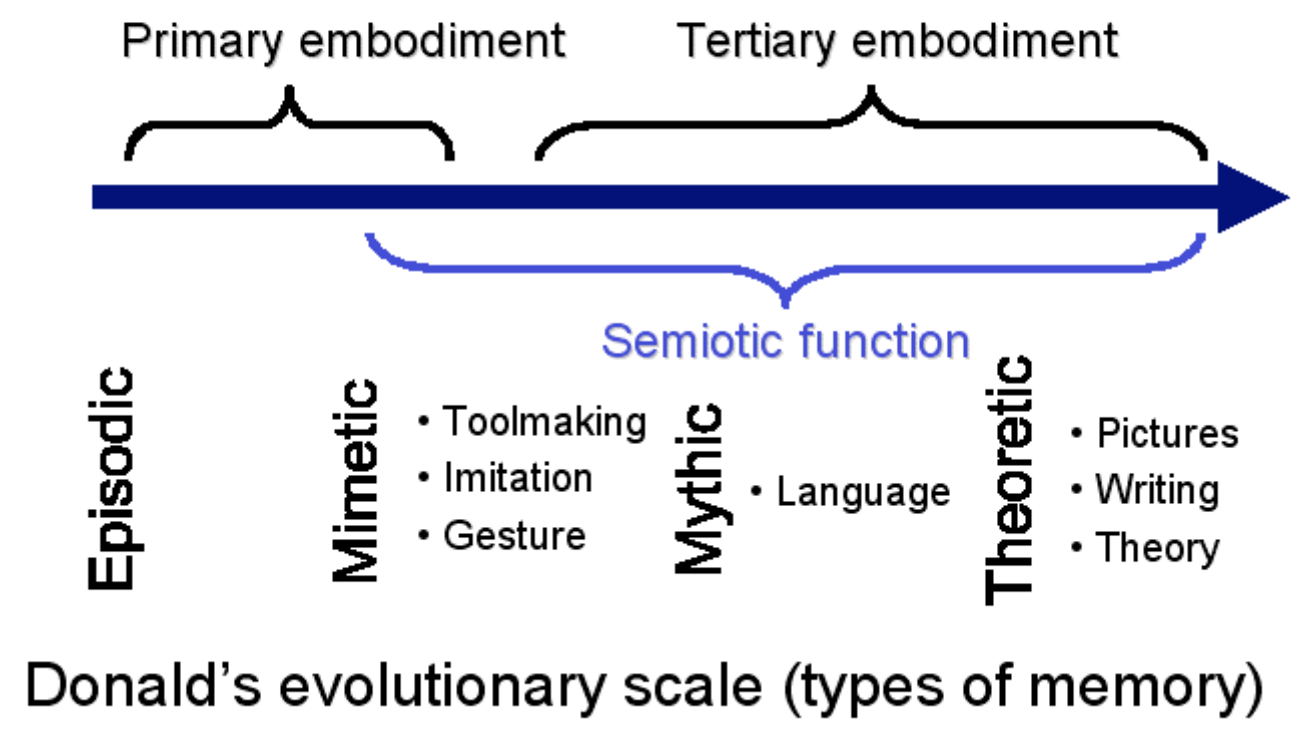

Fig 1. Donald's developmental scheme related to the notion of semiotic function. As understood here, primary embodiment refers to the own body, tertiary embodiment involves organism-independent displays, and secondary embodiment (not discussed here) is the body of the other. 


\begin{tabular}{|c|c|c|}
\hline $\begin{array}{l}\text { Type of } \\
\text { memory }\end{array}$ & $\begin{array}{l}\text { Type of } \\
\text { accumulation }\end{array}$ & $\begin{array}{l}\text { Type of } \\
\text { embodiment }\end{array}$ \\
\hline Episodic & $\begin{array}{l}\text { Attention span (event } \\
\text { in time/space) }\end{array}$ & - \\
\hline Mimetic & $\begin{array}{l}\text { Action sequence co- } \\
\text { owned by Ego and } \\
\text { Alter }\end{array}$ & Own body \\
\hline Mythic & $\begin{array}{l}\text { Transient artefact co- } \\
\text { produced by Ego and } \\
\text { Alter }\end{array}$ & $\begin{array}{l}\text { In the interaction } \\
\text { between Ego and Alter }\end{array}$ \\
\hline Theoretic & $\begin{array}{l}\text { Enduring artefact co- } \\
\text { externalised by Ego } \\
\text { and Alter }\end{array}$ & $\begin{array}{l}\text { External in relation to } \\
\text { Ego and Alter }\end{array}$ \\
\hline
\end{tabular}

Fig 2. Donald's memory types analysed in relation to the nature of accumulation 


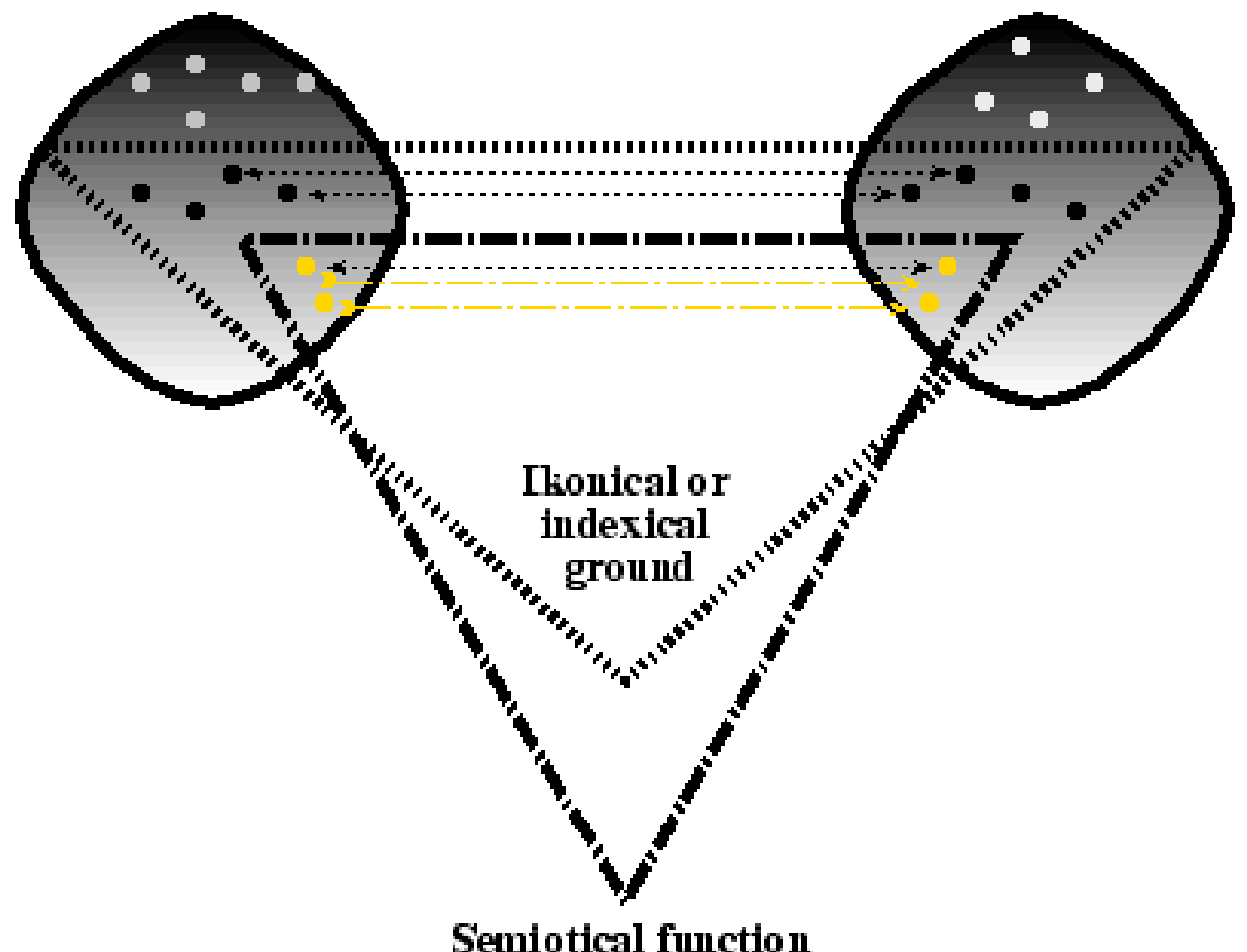

Fig. 3. The sign as a mapping between different spaces, based on different principles of relevance 


\begin{tabular}{|l|l|l|l|}
\cline { 2 - 4 } \multicolumn{1}{l|}{} & Firstness & Secondness & Thirdness \\
\hline Principle & Iconicity & - & - \\
\hline Ground & Iconic ground & $\begin{array}{l}\text { Indexicality }= \\
\text { indexical ground }\end{array}$ & - \\
\hline Sign & $\begin{array}{l}\text { Iconic sign } \\
\text { (icon) }\end{array}$ & $\begin{array}{l}\text { Indexical sign } \\
\text { (index) }\end{array}$ & $\begin{array}{l}\text { Symbolicity }= \\
\text { symbolic ground }= \\
\text { symbolic sign } \\
\text { (symbol) }\end{array}$ \\
\hline
\end{tabular}

Fig. 4. The relationship between principles, grounds, and signs, from the point of view of Peirce. 


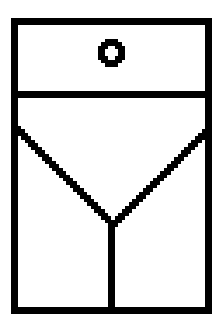

a

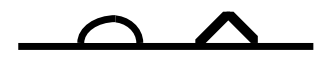

b

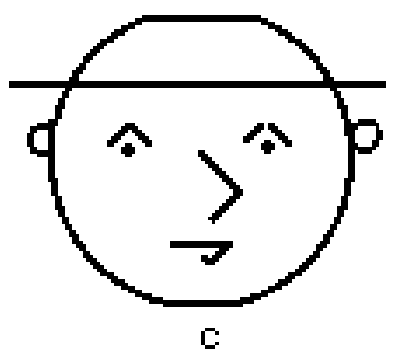

C

Fig. 5. Two droodles and a picture which can be read as a droodle: a) Olive dropping into Martini glass or Close-up of girl in scanty bathing suit (inspired from Arnheim as adapted in Sonesson 1992). b) Carraci's key (Mason behind wall); c) either a picture of a face or droodle which might represent a jar 